\title{
New Polyoxygenated Cyclohexenes from Uvaria kweichowensis and Their Antitumour Activities
}

\author{
Qiong-Ming Xu, Zhong-Mei Zou, Li-Zhen Xu,* and Shi-Lin YANG \\ Institute of Medicinal Plant Development, Peking Union Medical College and Chinese Academy of Medical Sciences; \\ Beijing 100094, P. R. China. Received January 5, 2005; accepted March 23, 2005
}

\begin{abstract}
Two new polyoxygenated cyclohexenes, kweichowenol $A$ and $B$, were isolated from the leaves of Uvaria kweichowensis, and their structures were established on the basis of their spectral data. The two new compounds showed some antitumour activity by MTT assay.
\end{abstract}

Key words Annonaceae; Uvaria kweichowensis; leaf; cyclohexene; kweichowenol A; kweichowenol B

Over the past two decades and more, the Uvaria genus has been found to be a rich source of polyoxygenated cyclohexenes, some of which exhibited antitumour, antileukemic or antibiotic activity. ${ }^{1,2)}$ Uvaria kweichowensis is a nongovernmental herb used to cure inflammation and tumour in the Southwest area of China. During the course of our investigation for antitumour agents from the chloroform extract of the leaves of Uvaria kweichowensis, two new crystalline compounds, kweichowenol A (1) and B (2), together with two known compounds, zeylenol (3) ${ }^{3)}$ and uvarigranol $\mathrm{G}(\mathbf{4}){ }^{4)}$ were obtained. We now report the isolation and structural elucidation of the two new compounds, as well as the evaluation of their antitumour activity.

\section{Results and Discussion}

Kweichowenol A (1) was obtained as white needles. The molecular formula was determined to be $\mathrm{C}_{24} \mathrm{H}_{24} \mathrm{O}_{7}$ by high resolution (HR)-electrospray ionization (ESI)-mass spectrometry. The IR spectrum of compound 1 suggested the presence of hydroxyl group(s) (3587, 3454, 1115, $1090 \mathrm{~cm}^{-1}$ ), ester group(s) (strong absorption at $1722 \mathrm{~cm}^{-1}$ ) and monosubstituted phenyl $(\mathrm{Ph}) \operatorname{ring}(\mathrm{s})(1601,1454,710$ $\left.\mathrm{cm}^{-1}\right)$. The UV spectrum gave absorption maxima at $\lambda$ 230, 274 and $280 \mathrm{~nm}$, indicating the presence of one or two benzoyl (Bz) group(s).

The most informative evidence for the structural elucidation of compound $\mathbf{1}$ was derived from its ${ }^{1} \mathrm{H}-\mathrm{NMR}$ spectral data, which, together with those of other related compounds, were summarized in Table 1. The aromatic proton signals between $\delta 7.4-8.2(10 \mathrm{H}, \mathrm{m})$ confirmed the presence of two benzoyl groups, whilst the isopropylidene moiety in the structure was indicated by the proton signals at $\delta 1.31$ $(3 \mathrm{H}, \mathrm{s})$ and $1.46(3 \mathrm{H}, \mathrm{s})$. The ${ }^{1} \mathrm{H}-\mathrm{NMR}$ spectrum also showed two olefinic proton signals at $\delta 5.82(2 \mathrm{H}, \mathrm{m})$ and a carbinyl proton signal (secondary alcohol) at $\delta 4.28$. The two benzoxy groups appeared to locate at C-3 and C-6 based upon the down-field shifts of $\mathrm{H}-3$ at 5.60 and $\mathrm{H}-6$ at 5.79, whilst the isopropylidene group was established at $\mathrm{C}-1$ and $\mathrm{C}-7$ on the basis of the down field shifts of $\mathrm{H}-7$ at $\delta 4.37$ and 4.32. The elucidation of compound 1 was supported by the existence of the fragment ion peaks at $\mathrm{m} / \mathrm{z} 294$ and 130 resulted from the typical retro-Diels-Alder (RDA) cleavage of the molecule of compound $\mathbf{1}$ in the EI-MS spectrum. In comparison with the ${ }^{1} \mathrm{H}-\mathrm{NMR}$ spectral data of uvarigranol $\mathrm{F}^{5)}$ the coupling constant $J_{2,3}$ of $8.4 \mathrm{~Hz}$ suggested that $\mathrm{H}-2$ and $\mathrm{H}-3$ were favorably located at axial position. In addition, $J_{5,6}$ of $2.4 \mathrm{~Hz}$ suggested that the benzoxy group at C- 6 was likely located at the pseudo-equatorial position. ${ }^{6)}$

The proposed structure of compound $\mathbf{1}$ was verified by the heteronuclear multiple bond connectivity (HMBC) experiment (Fig. 1).

The relative stereochemistry of compound $\mathbf{1}$ was further established from its nuclear overhauser effect spectroscopy (NOESY) spectrum. Interactions between H-3 $(\delta$ 5.64) and $\mathrm{H}-7(\delta 4.37,4.32)$ indicated that they were on the same side of the molecule, while those between H-2 ( $\delta$ 4.28) and H-6 ( $\delta$ 5.79) suggested that H-2 and H-6 were on the other side.

The circular dichroism (CD) spectrum of compound 1 exhibited a split curve centered at $\lambda 227 \mathrm{~nm}$ with a positive cotton effect at $\lambda 235(+3.42)$ and a negative cotton effect at

Table 1. ${ }^{1} \mathrm{H}(600 \mathrm{MHz})$ and ${ }^{13} \mathrm{C}(150 \mathrm{MHz})$ NMR Data of Compounds $\mathbf{1}$ and $2\left(\mathrm{CDCl}_{3}, 25^{\circ} \mathrm{C}\right)$

\begin{tabular}{|c|c|c|c|c|}
\hline & \multicolumn{2}{|c|}{1} & \multicolumn{2}{|c|}{2} \\
\hline & $\delta_{\mathrm{C}}$ & $\delta_{\mathrm{H}}$ & $\delta_{\mathrm{C}}$ & $\delta_{\mathrm{H}}$ \\
\hline 1 & 85.4 & & 74.5 & \\
\hline 2 & 72.1 & $4.28 \mathrm{~d}(8.4)$ & 77.2 & $3.88 \mathrm{~d}(10.2)$ \\
\hline 3 & 73.7 & $5.60 \mathrm{dd}(8.4,2.4)$ & 72.3 & $4.29 \mathrm{dd}(10.2,7.8)$ \\
\hline 4 & 129.1 & $5.82 \mathrm{~m}$ & 76.0 & $5.63 \mathrm{dd}(7.8,2.4)$ \\
\hline 5 & 127.4 & $5.82 \mathrm{~m}$ & 126.8 & $5.78 \mathrm{dd}(10.2,2.4)$ \\
\hline 6 & 74.1 & $5.79 \mathrm{~m}$ & 133.6 & 5.83 dd $(10.2,1.8)$ \\
\hline 7 & 64.3 & $4.37 \mathrm{~d}, 4.32 \mathrm{~d}(8.4)$ & 66.2 & $4.58 \mathrm{~d}, 4.50 \mathrm{~d}(10.8)$ \\
\hline $\mathrm{Ar}$ & $120-140$ & $7.4-8.2 \mathrm{~m}$ & $120-140$ & $7.3-8.1 \mathrm{~m}$ \\
\hline Carbonyl & $167.2,167.5$ & & $167.0,167.2$ & \\
\hline Isopropylidene & $110.9,25.9,26.8$ & $1.46 \mathrm{~s}, 1.31 \mathrm{~s}$ & & \\
\hline
\end{tabular}

Data in parentheses are $J$ values (in $\mathrm{Hz}$ ). 


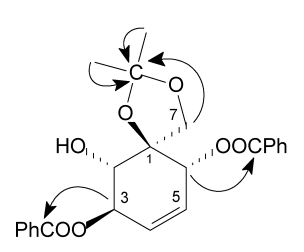

1

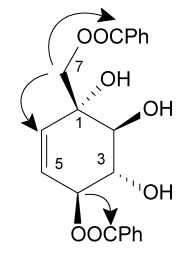

2
Fig. 1. Key HMBC Correlation of Compounds $\mathbf{1}$ and $\mathbf{2}$
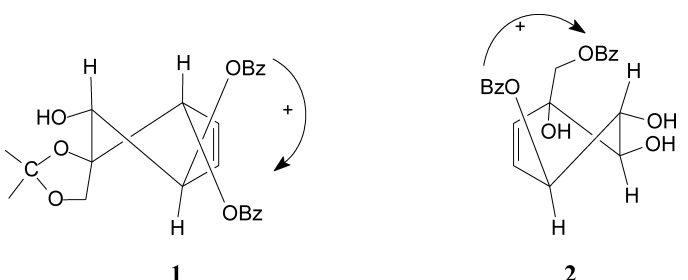

2

Fig. 2. The Chirality of the Dibenzoate of Compounds 1 and 2

$\lambda 219(-8.20)$, indicating the clockwise manner for the orientation of the two benzoxy groups at C-3 and C-6 (Fig. 2), thus the absolute configuration was established as $1 R, 2 S, 3 R, 6 R$.

In order to determine whether compound $\mathbf{1}$ was naturally occurring in the leaves of Uvaria kweichowensis, the leaves were extracted with $\mathrm{CHCl}_{3}$, and the resultant extract was subjected to HPLC analysis. The HPLC analysis demonstrated the presence of kweichowenol $\mathrm{A}$ in $\mathrm{CHCl}_{3}$ extract of the leaves of Uvaria kweichowensi. Such a result indicated that compound $\mathbf{1}$ occurred naturally, rather than as a consequence of the utilization of acetone during the separation procedure.

Kweichowenol B (2) was obtained as white solid. The molecular formula was determined to be $\mathrm{C}_{21} \mathrm{H}_{20} \mathrm{O}_{7}$ by HRESI-mass spectrometry. Compound 2 had similar IR and UV spectra to those of compound 1. Its ${ }^{1} \mathrm{H}-\mathrm{NMR}$ spectrum displayed the signals of two benzoxy groups $(\delta 7.3-8.1,10 \mathrm{H}$, $\mathrm{m})$ and the seven protons on a methyl-cyclohexene skeleton ( $\delta 3.8-5.9$ ) (the assignment shown in Table 1). Among the latter signals, an $\mathrm{AB}$ quartet at $\delta 4.50$ and $4.58(10.8 \mathrm{~Hz})$ was attributed to the two methylene protons at $\mathrm{C}-7$, similar to those of the known polyoxygenated cyclohexenes. However, the coupling pattern of the other five protons was markedly different from those of the known compounds.

The HMBC spectrum of compound 2 (Fig. 1) indicated that H-7 $(\delta 4.50,4.58)$ correlated with the olefinic carbon at $\delta 133.6$, such a result supported that the double bond located at C-5/C-6 instead of the usual C-4/C-5 position in the known compouds. The correlations between $\mathrm{H}-7$ and the ester carbonyl at $\delta 167.2$ and between H-4 ( $\delta$ 5.63) and the ester carbonyl at $\delta 167.0$ indicated that the two benzoxyl groups located at C-4 and C-7, respectively. These assignments were further confirmed by the presence of the fragment ion at $\mathrm{m} / \mathrm{z} 249$ due to the loss of benzoxyloxymethyl segment from the $[\mathrm{M}]^{+}$and the diene ion at $m / z 324$ due to RDA cleavage in the EI-MS spectrum.

Based upon a careful analysis of the coupling constants and the correlations shown in the NOESY spectrum, the relative stereochemistry of compound $\mathbf{2}$ was established. The $J_{2,3}$ value of $10.2 \mathrm{~Hz}$ revealed that both $\mathrm{H}-2$ and $\mathrm{H}-3$ located at axial positions, whilst the $J_{3,4}$ value of $7.8 \mathrm{~Hz}$ revealed the pseudo-axial orientation of $\mathrm{H}-4$. In the NOESY spectrum of uvarigranol I, ${ }^{4} \mathrm{H}-2$ correlated with $\mathrm{H}-7$, however, correlation between $\mathrm{H}-3$ and $\mathrm{H}-7$ was observed in the NOESY spectrum of compound 2, so the benzoxyloxymethyl group of compound $\mathbf{2}$ was deduced to locate at pseudo-axial position.

The CD spectrum of compound 2 exhibited a positive cotton effect at $\lambda 235.5(+5.08)$ and a negative cotton effect at $\lambda$ $218.5(-4.09)$, indicating that the two benzoxy groups were oriented in a clockwise manner. Since the overall relative configuration was known, the absolute configuration of compound 2 was established as $1 R, 2 S, 3 S, 4 S$.

Compound 2 is a stereoisomer of piperenol $\mathrm{B},{ }^{7)}$ the absolute configuration of which was reported as $1 S, 2 S, 3 S$, $4 R$, and the differences between them were in their configurations at $\mathrm{C}-1$ and $\mathrm{C}-4$.

In the case of bioactivities of compounds 1, 2, 3 and 4, antitumour activities of them were expressed as $\mathrm{IC}_{50}$ values. As determined by MTT assay, the $\mathrm{IC}_{50}$ values of compounds 1, 2, 3 and 4 for A549 bronchogenic carcinoma cell were 65, 20, 28 and $25 \mu \mathrm{g} / \mathrm{ml}$ respectively, for SK-MES-1 bronchogenic carcinoma cell those were $56,18,26$ and $23 \mu \mathrm{g} / \mathrm{ml}$, and for NCI-H446 bronchogenic carcinoma cell those were $50,23,30$ and $26 \mu \mathrm{g} / \mathrm{ml}$. The results suggested that antitumour activity of compound $\mathbf{2}$ was a little better than those of the other three compounds.

\section{Experimental}

General Procedures ${ }^{1} \mathrm{H}-,{ }^{13} \mathrm{C}-\mathrm{NMR}$ and $2 \mathrm{D}$ NMR spectra were recorded on a Varian Inova 600 spectrometer in $\mathrm{CDCl}_{3}$ using tetramethylsilane (TMS) as internal standard. EI-MS and FAB-MS spectra were determined on a Micromass Zabspec spectrometer. HR-ESI-MS spectra were determined on a Q-TOF2 spectrometer. CD spectra were determined on a JASCO-715 spectrometer. Preparative HPLC was carried out on a column of Phenyl $(250 \times 9.4 \mathrm{~mm}$ i.d., Zorbax $)$ with a Waters 2996 detector, the flow rate was $3 \mathrm{ml} / \mathrm{min}$ and the wave length for detection was $230 \mathrm{~nm}$. Silica gel (200-300 mesh) for column chromatography was obtained from Qingdao Marine Chemical Factory, Qingdao, People's Republic of China. Precoated plates of silica gel GF254 were used for TLC, and detected under UV.

Plant Material The leaves of Uvaria kweichowensis were collected in Guizhou province of China in November 2002, and identified by Professor Shou-Quan Lin and Doctor Guo-Qiang Li of our institute. A voucher sample is deposited in the Herbarium of the Institute of Medicinal Plant Development, Peking Union Medical College.

Extraction and Isolation The dried plant material $(5 \mathrm{~kg})$ was extracted three times with $95 \% \mathrm{EtOH}$ under reflux. The solvent was subsequently dried under reduced pressure conditions, the residue partitioned between $\mathrm{CHCl}_{3}$ and $\mathrm{H}_{2} \mathrm{O}$, and the $\mathrm{CHCl}_{3}$-soluble fraction were further portioned between petroleum and $90 \% \mathrm{MeOH}$. The $90 \% \mathrm{MeOH}$ fraction $(85 \mathrm{~g}$ ) was chromatographed over silica gel column, which was eluted with petroleum-EtOAc gradients to afford 25 combined fractions (F1-F25). Further purification of F7 and F18 using sephadex LH-20 column chromatography (eluted by $\left.\mathrm{CHCl}_{3}-\mathrm{MeOH}, 1: 1\right)$ yielded kweichowenol A (1) $(40 \mathrm{mg})$ and kweichowenol B (2) (25 mg). Zeylenol (3) $(500 \mathrm{mg}$ ) and uvarigranol G (4) $(800 \mathrm{mg})$ were obtained from F15 through RP-HPLC using $\mathrm{MeOH}-\mathrm{H}_{2} \mathrm{O}$ $(80: 20)$ as eluents.

Kweichowenol A (1): White needles, mp $51-53^{\circ} \mathrm{C} .[\alpha]_{\mathrm{D}}^{20}-95.8^{\circ}$ $\left(c=0.0011, \mathrm{CHCl}_{3}\right)$. UV $\lambda_{\max }\left(\mathrm{CHCl}_{3}\right) \mathrm{nm}: 230,274,280$. IR $(\mathrm{KBr}) \mathrm{cm}^{-1}$ : 3587, 3454, 1722, 1601, 1454, 1273, 1115, 710. EI-MS m/z: 409 (15), 294 (3.5), 273 (3.5), 244 (2.0), 227 (8.5), 203 (9.0), 130 (5.5), 122 (10.2), 105 (100), 77 (32). HR-ESI-MS m/z: $425.1598\left([\mathrm{M}+\mathrm{H}]^{+}\right), 447.1397([\mathrm{M}+$ $\left.\mathrm{Na}]^{+}\right), 463.1138\left([\mathrm{M}+\mathrm{K}]^{+}\right) \cdot{ }^{1} \mathrm{H}-$ and ${ }^{13} \mathrm{C}-\mathrm{NMR}$ data see Table 1.

Kweichowenol B (2): White solid, mp $166-167^{\circ} \mathrm{C} .[\alpha]_{\mathrm{D}}^{20}-5.78^{\circ}$ $\left(c=0.0019, \mathrm{CHCl}_{3}\right)$. UV $\lambda_{\max }\left(\mathrm{CHCl}_{3}\right) \mathrm{nm}: 230,274,280$. IR $(\mathrm{KBr}) \mathrm{cm}^{-1}$ : $3438,3261,1728,1701,1599,1583,1452,1271,1115,712$. EI-MS $m / z$ : 367 (0.3), 249 (20), 231 (18), 140 (6.0), 123 (18), 122 (10.2), 105 (100), 77 (48). HR-ESI-MS $m / z: 385.1284\left([\mathrm{M}+\mathrm{H}]^{+}\right), 407.1067\left([\mathrm{M}+\mathrm{Na}]^{+}\right)$, $423.1067\left([\mathrm{M}+\mathrm{K}]^{+}\right) .{ }^{1} \mathrm{H}-$ and ${ }^{13} \mathrm{C}-\mathrm{NMR}$ data see Table 1. 
Anti-tumor Bioassays To evaluate the antiproliferative effect of compounds on A549, SK-MES-1 and NCI-H446 bronchogenic carcinoma cell lines, the MTT colorimetric assay was performed. The amount of formazan was determined by photometer at $570 \mathrm{~nm}$. Cell were plated into 96-well flatbottomed cultured plates at a concentration $5 \times 10^{4}$ cell per well in complete RPMI 1640 culture medium. Twenty-four hours after plating, the medium containing foetal calf serum was removed and test solutions were given to cells in various final concentrations such as $10,25,50,100,200 \mu \mathrm{g} / \mathrm{ml}$. After incubation with drugs for $24 \mathrm{~h}$, MTT solution was added to the wells and plates were incubated at $37^{\circ} \mathrm{C}$ for $4 \mathrm{~h}$. Results were expressed as percentage of the absorbance in control cells compared to that in the drugtreated cells.

Acknowledgements This project was supported by the National Natural Sciences Foundation of China (No. 30472077) and the Natural Sciences Foundation of Beijing City (No. 7052049). We also want to express our thanks to Professor Chao-Yi Deng in the Institute of Forestry of Guizhou province in China for the collection of plant material.

\section{References}

1) Leboeuf M., Cave A., Bhaumik P. K., Mukherjee B., Mukherjee R., Phytochemistry, 21, 2783-2813 (1982).

2) Nkunya M. H. H., Weenen H., Koyl N. J., Thus L., Zwanenburg B., Phytochemistry, 26, 2563-2565 (1987).

3) Jolad S. D., Hoffmann J. J., Schram K. H., Cole J. R., Temperta M. S., Bates R. B., J. Org. Chem., 46, 4267-4272 (1981).

4) Pan X.-P., Chen R.-Y., Yu D.-Q., Phytochemistry, 47, 1063-1066 (1998).

5) Pan X.-P., Yu D.-Q., He C.-H., Chai J.-J., Acta Pharmaceutica Sinica, 32, 530-535 (1997).

6) Abraham R. J., Gottschalck H., Paulsen H., Thomas W. A., J. Chem. Soc., 1965, 6268-6277 (1965).

7) Taneja S. C., Koul S. K., Pushpangadan P., Dhar K. L., Daniewski W. M., Schilf W., Phytochemistry, 30, 871-874 (1991). 